\title{
Analysis of a below-knee patellar tendon-bearing prosthesis: A finite element study
}

Peter Quesada, PhD and Harry B. Skinner, MD, PhD

Intercampus Graduate Group in Bioengineering, University of California, Berkeley/San Francisco, CA 94720;

Department of Orthopedic Surgery, University of California, San Francisco, San Francisco, CA 94143-0728;

Rehabilitation Research and Development Service, VA Medical Center, San Francisco, CA 94143

\begin{abstract}
In this study, a finite element (FE) model of a belowknee prosthesis of patellar tendon-bearing (PTB) design, and several altered variations of the model have been constructed. A load of approximately 1.5 times normal body weight $(984 \mathrm{~N})$ was applied at the heel of the model to simulate heelstrike conditions. The "base" model was then analyzed and revised iteratively until a model which provided consistency between soft tissue elastic modulus and socket displacement was developed. The interface normal and shear stresses obtained from the analysis of this revised base model were highest (about 961, and $463 \mathrm{KPa}$, respectively) at the distal anterior tip of the socket/stump. Proximally, higher normal stresses (72-78 KPa) were found medially and posteriorly. Proximal shear stresses were highest posteriorly (79 KPa), although shear stresses medially ( $51 \mathrm{KPa})$, and laterally ( $43 \mathrm{KPa})$, were also much higher than anteriorly $(10 \mathrm{KPa}) . \mathrm{FE}$ analyses were performed on the altered models to determine the relative effects on socket/stump interface stresses of altering the FE model of the prosthesis.

Results of the analysis indicate that fabricating the prosthesis from a material with an elastic modulus ten times lower than that of the revised base model can produce reductions in the maximum pressure of up to 14 percent. Large decreases in maximum pressures ( 71 percent) resulted from the use of a suction socket rather than a conventional socket. Small changes in stump length $(2 \mathrm{~cm})$ caused relatively large pressure changes (16 to 18 percent).
\end{abstract}

Key words: amputees, below-knee (BK) prosthesis, elastic modulus, finite element ( $F E$ ) model, patellar tendon-bearing (PTB) design, socket/stump interface stress.

Address all correspondence and reprint requests to: Dr. Harry B. Skinner, Department of Orthopedic Surgery, Room U454, University of California at San Francisco, San Francisco, CA 94143-0728.

\section{INTRODUCTION}

Of the approximately 60,000 amputations performed each year in the United States, a majority are below-knee (BK) amputations (21). BK amputees who are fitted with prostheses often have difficulty walking $(3,14,17,20)$; many of these because the prostheses are painful and heavy (6).

While early fitting of a prosthesis can improve an amputee's ability to successfully adapt to a prosthesis, postoperative stump complications (e.g., infection, venous thrombosis, pulmonary embolism) can complicate this effort (21). Many amputees eventually prefer wheelchair mobility to ambulating with a prosthesis because the latter is too uncomfortable, painful, or energy-costly.

Research devoted to improving the comfort of wearing a BK prosthesis, thus improving ambulation, has often focused on stump/socket interface pressures. These pressures are better referred to as normal stresses, because they are not strictly hydrostatic, and include a shear component. The term "normal stress" will be used in this paper to denote what has been called "pressure" in the literature. Previously, investigators have experimentally measured these normal stresses in BK amputees, but a wide variation in results are reported $(11,12,18)$. There are methodological differences among these different studies which may account for the lack of specific agreement among these results. However, these normal stress data do provide a general basis of comparison to analytical studies.

Naeff and Van Pijkeren used parameter variation in addressing the problem of prosthesis comfort in above-knee (AK) amputees (8). Sockets with various brim shapes were fabricated and then worn by amputees to determine the 
effect of brim shape variation on normal stress distribution and comfort.

To avoid having to actually fabricate and clinically test prostheses (which is costly and time-consuming), Nissan conceptualized a model of the BK stump to determine stump forces, and varied its parameters to determine what effect these variations would have on force transmission at the interface (10). In this analysis, however, the locations of the forces acting on the model were assumed to be known, so the model was unable to predict the specific locations of the greatest stress on the stump.

The finite element method (FEM) has been used to address a variety of orthopedic problems (7). Steege et al. used the FEM to model the BK stump to determine whether interface pressures could be predicted (18). Although they were able to calculate normal stresses having a range similar to that of their measured values, their calculated normal stresses still lacked complete agreement with their measured normal stresses at specific locations.

In the present study, emphasis in the use of the FEM was shifted from that of attempting to calculate absolute stresses to that of trying to determine the relative effects on the stresses of altering the model being analyzed. This shift in emphasis was aimed primarily at evaluating the possibility that changes in the design and fabrication of BK prostheses may bring about reduced socket/stump interface stresses, which could lead to improved prosthesis comfort. In the current investigation, an FE model of a $\mathrm{BK}$ prosthesis of patellar tendon-bearing (PTB) design, and several altered variations of the model were developed. FE analysis was performed on the "base" and "altered" models. Results of the base model were compared with previous experimental and analytical investigations to assess whether the results obtained here were of reasonable range and magnitude. Of primary interest was how the interface stresses obtained for the altered models compared with those of the base model. Changes in the base model that resulted in lower stresses were identified.

\section{METHODS}

A three-dimensional FE model of a right, exoskeletal, PTB below-knee prosthesis, approximately $56-\mathrm{cm}$ long, with a 17-cm long socket was constructed (Figure 1). The model contained quadrilateral and triangular shell elements with plane and bending stress behavior. Each element was assigned a thickness of $\mathrm{t}=0.5 \mathrm{~cm}$ (thickness of the actual prosthesis is variable, ranging from about $0.25 \mathrm{~cm}$ to 0.6 $\mathrm{cm})$. The coordinates of the nodes for the shank and foot

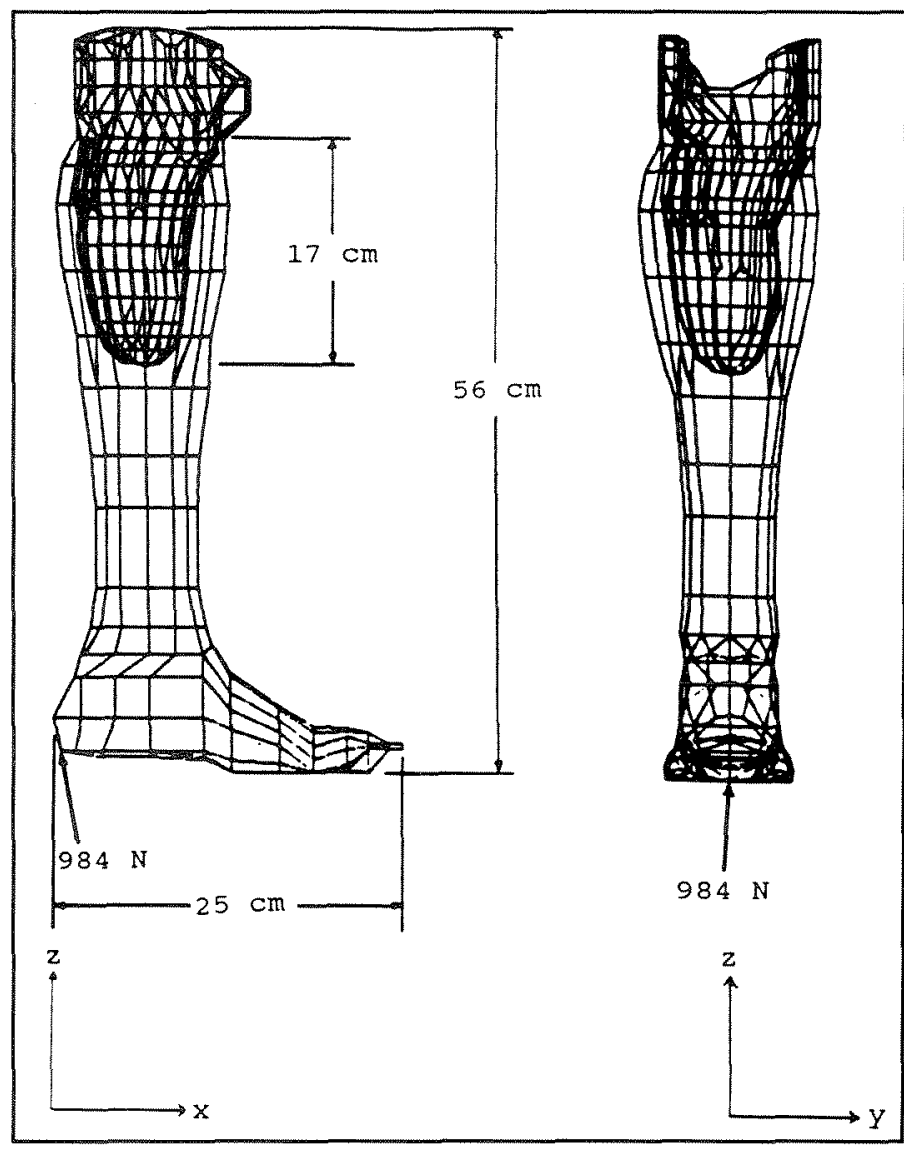

Figure 1.

(Left) Lateral view of FEM model of the right below-knee prosthesis showing loading conditions and dimensions.

(Right) Anterior view.

were determined by direct measurement, while those for the socket were determined by digitization of tracings of slices of a mold of the socket. Measurements were taken from an available, discarded prosthesis which provided a realistic template for our generic FE model. The base model contained 636 nodes and 655 elements. The material properties of the base model correspond to those of an isotropic composite of polyester resin and fiberglass (Table 1). The assumption of isotropy was implicit in the use of SAP80 shell elements, as each of these elements supports only a single set of material properties. A hard socket with the same material properties was assumed without intervening stump socks or liner. The socket was connected at its brim to the top of the prosthetic shank with a row of elements of the same material properties.

At any point where the socket and stump soft tissue are in contact, the tissue exerts a force on the socket. To model the soft tissue generating these forces, each node within the model of the socket was supported by a spring 
with linear spring constants in each of the $\mathrm{x}, \mathrm{y}$, and $\mathrm{z}$ component directions. Thus, each of these three springs, attached at a node, sustains axial load in each component direction, and the total load on each spring is

$$
\mathbb{F}=K_{\mathrm{x}} \mathbf{d}_{\mathrm{x}}+\mathrm{K}_{\mathrm{y}} \mathrm{d}_{\mathrm{y}}+\mathbb{K}_{\mathrm{z}} \mathrm{d}_{\mathrm{z}}
$$

The force on the socket at any node within the socket was considered as the sum of two forces. One force is caused by stretching or shearing parallel to the interface between the skin at the interface, and skin layers below,

$$
\mathbb{F}_{\text {parallel }}=K_{\text {parallel }, x} d_{x}+K_{\text {parallel }, y} d_{y}+K_{\text {parallel }, z} d_{z} \text {. }
$$

The other force is caused by compression of the tissue perpendicular to the surface,

$\mathbf{F}_{\text {perpend }}=K_{\text {perpend, } \mathrm{x}} \mathbf{d}_{\mathrm{x}}+\mathrm{K}_{\text {perpend }, \mathrm{y}} \mathbf{d}_{\mathrm{y}}+\mathbf{K}_{\text {perpend }, \mathrm{z}} \mathbb{d}_{\mathrm{z}}$.

Thus, the spring constant in each of the $x, y$, and $z$ component directions was calculated as the sum of the corresponding direction components of the parallel (skin tensile) spring constant and perpendicular (soft tissue compressive) spring constant.

At each node within the socket, a parallel (skin tensile) spring constant, $K_{\text {parallel }}$ (prior to resolution into direction components), of $25 \mathrm{~N} / \mathrm{cm}$ was approximated from available data (1). The unresolved perpendicular (soft tissue compressive) spring constant was calculated from the relationship

$$
\mathrm{K}_{\text {perpend }}=\mathrm{AE} / \mathrm{L}
$$

where $A, E$, and $L$ are, respectively, the surface area, elastic modulus, and thickness of the soft tissue represented by the spring supporting that node.

Soft tissue at the distal end of the stump was modeled as $1.0-\mathrm{cm}$ thick (i.e., $\mathrm{L}=1.0 \mathrm{~cm}$ ). Proximal to the distal end, soft tissue in contact with the anteromedial tibia was modeled as being $0.35-\mathrm{cm}$ thick. This would correspond to a mature stump soft tissue thickness. All other anterior soft tissue was modeled as being $0.75-\mathrm{cm}$ thick, and all posterior soft tissue was taken as $1.5-\mathrm{cm}$ thick. As the primary intent of this study was to compare the results of the altered models with those of the base model, rather than to predict absolute results, a limited number of softtissue thicknesses were chosen. This was done as a compromise between simplifying the construction and alteration of the model, and approximating the thickness of soft tissue in the stump, such that soft tissue nearest to the anteromedial tibia had the lowest thickness, posterior soft tissue was thickest, and anterolateral soft tissue had a thickness intermediate to these two. Also, while dimensions were taken from an actual prosthesis, the model represented a
Table 1.

Material properties of components of BKA prosthesis and socket.

\begin{tabular}{lcccc}
\hline $\begin{array}{l}\text { Material } \\
\text { Modulus (MPa) }\end{array}$ & $\begin{array}{c}\text { Specific } \\
\text { Gravity }\end{array}$ & $\begin{array}{c}\text { Poisson's } \\
\text { Ratio }\end{array}$ & Reference \\
\hline $\begin{array}{l}\text { Fiberglass-reinforced } \\
\text { polyester resin }\end{array}$ & $1.4 \times 10^{4}$ & 1.9 & 0.13 & 22 \\
$\begin{array}{l}\text { Fiberglass- } \\
\text { reinforced epoxy }\end{array}$ & $3.9 \times 10^{4}$ & 1.84 & 0.13 & 22 \\
\begin{tabular}{l} 
Polystyrene \\
\hline \hline
\end{tabular}
\end{tabular}

"generic" prosthesis; thus, specific measurement of stump soft tissue was not possible.

The surface area of soft tissue associated with a node, A, was calculated as the sum of one-fourth of the area of all quadrilateral elements, and one-third of the area of all triangular elements sharing the node. The soft tissue elastic modulus, $\mathrm{E}$, was calculated from the equation

$$
\mathrm{E}=\mathrm{a} \varepsilon^{3}+\mathrm{b} \varepsilon^{2}+\mathrm{c} \varepsilon
$$

where $\varepsilon$ is normal strain, and the constants $a, b$, and $c$, determined to be $2,743,-1,010$, and 267.4 , respectively, were obtained by fitting a cubic curve to literature data (9). $\mathrm{E}$ is expressed as $\mathrm{N} / \mathrm{cm}^{2}$, and $\varepsilon$ is unitless. For the base model, $\varepsilon$ (and subsequently, $\mathbb{E}, K_{\text {perpend }}, K_{x}, K_{y}$, and $K_{z}$ ) was determined from performing the analysis with an initial approximation $\left(K_{\mathrm{x}}=\mathrm{K}_{\mathrm{y}}=\mathrm{K}_{\mathrm{z}}=60 \mathrm{~N} / \mathrm{cm}\right)$ for the perpendicular (soft-tissue compressive) spring constant values corresponding to a few percent strain (Figure 2 is a flowchart of this process). This initial approximation was estimated to be between values obtained in subsequent calculations. The final upper-range values for elastic moduli along the anterior, posterior, medial, and lateral surfaces for the base model are shown in Table 2 . These moduli are much higher than the value used by Steege et al. (18); however, they correspond to a higher loading case. While the input data for the model seem appropriate, it should

Table 2.

Upper range strains and elastic moduli along the anterior, posterior, medial, and lateral surfaces for the revised base model.

\begin{tabular}{lcc} 
Surface & $\begin{array}{c}\text { Upper Range } \\
\text { Strains }\end{array}$ & $\begin{array}{c}\text { Upper Range } \\
\text { Elastic Moduli (KPa) }\end{array}$ \\
\hline Anterior & 0.518 & 2490 \\
Posterior & 0.171 & 300 \\
Lateral & 0.226 & 405 \\
Medial & 0.137 & 247 \\
\hline \hline
\end{tabular}




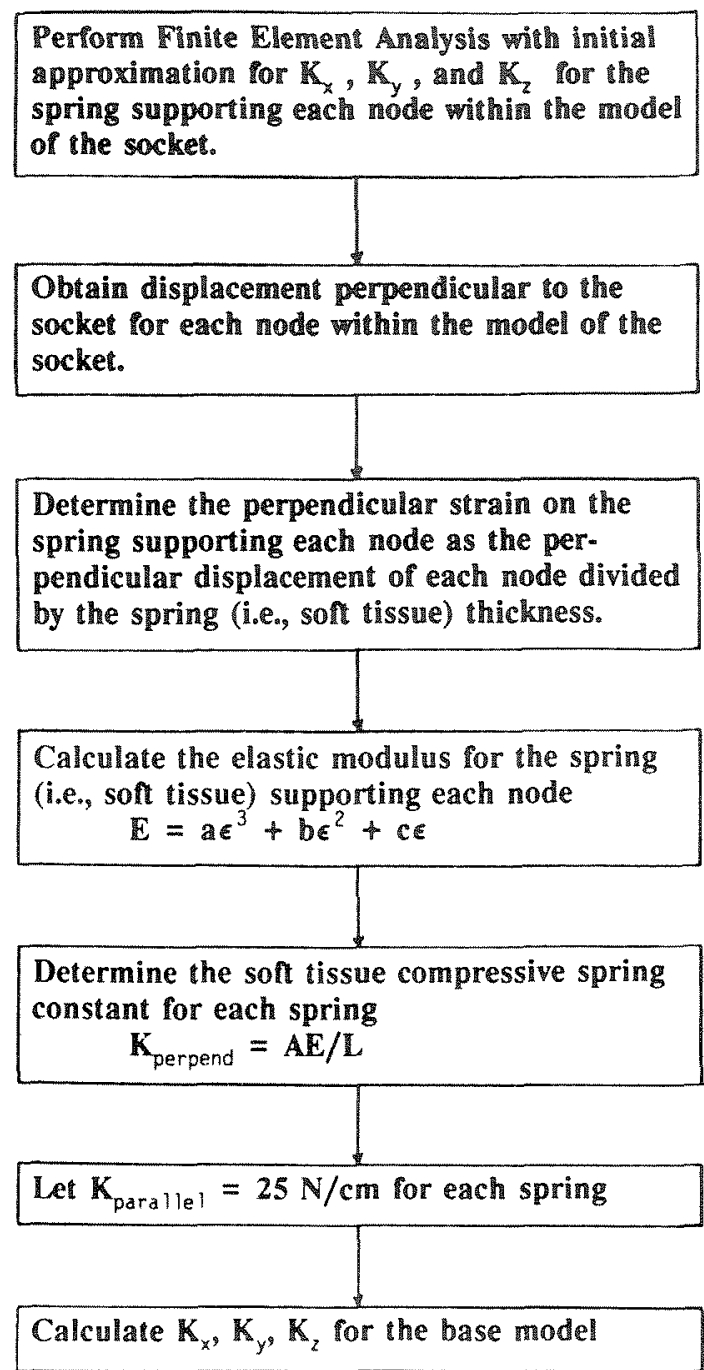

Figure 2.

Flowchart outlining the process of obtaining the initial base model.

be noted that it was drawn from diverse sources; its accuracy has an effect on the results.

The calculations in this analysis were carried out using the FEM program, SAP80 (Computers and Structures, Inc., Berkeley, CA). Plots of the model were generated by the program SAPLOT. Cross-sectional interface normal stress ("porcupine") plots were generated with the program GDA.

A resultant force of $984 \mathrm{~N}$ (18) (corresponding to approximately 1.5 times the body weight of a $68 \mathrm{~kg}$ person), equally distributed among three nodes located in the heel, was used as the loading condition (Figure 1). The force was applied at an angle of 9 degrees from the negative $\mathrm{Z}$-axis, -81 degrees from the positive $\mathrm{X}$-axis, and 88 degrees from the negative $\mathrm{Y}$-axis, in order to simulate the direction of the force at heelstrike (19). Thus, the bone of the stump was modeled as a rigid body that, at heelstrike, receives force from the prosthesis through a soft tissue envelope.

After the FE analysis was performed for the initial base model, the predicted displacement of each node within the socket was used to modify the supporting springs. First the $x, y$, and $z$ components of displacement for each node were identified. The total nodal displacement was determined as the vector sum of these components,

$$
\mathrm{d}=\mathrm{d}_{\mathrm{x}}+\mathrm{d}_{\mathrm{y}}+\mathbf{d}_{\mathrm{z}}
$$

The normal component of displacement was calculated as the dot product of the total displacement and the area normal unit vector,

$$
\mathrm{d}_{\mathrm{n}}=\mathbf{d} \cdot \mathbf{u}_{\mathrm{n}}
$$

where $u_{n}$ was the area normal unit vector directed away from the stump surface. The area normal unit vector at a node was calculated in the undeformed model by normalizing the sum of the cross-products of the vectors representing the adjacent edges of all the elements common to that node. The normal displacement divided by the soft tissue thickness yielded the normal strain of the spring supporting each node. This strain allowed $\mathrm{E}$, and subsequently $\mathrm{K}_{\text {perpend }}$, to be calculated. Second, any component of a node's displacement with the same sign as the corresponding component of the area normal unit vector at the node, such that the component of displacement is directed away from the stump surface, resulted in setting the corresponding component of $\mathrm{K}_{\text {perpend }}$ to zero. This adjustment more realistically modeled separation between the socket and the soft tissue. Performing the FE analysis and recomputing the spring constants was iterated until the maximum predicted strains of two consecutive analyses differed by less than 0.1 percent (Figure $\mathbf{3}$ is a flowchart of this process). The spring constants for the revised base model were computed from the last set of predicted strains.

The FE analysis was performed for the revised base model. Maximum principal stresses within the prosthesis were noted and compared with failure stress. Nodal forces in the socket were used to calculate interface normal stress at each node. For all nodes within the model of the socket, the force perpendicular to the surface was approximated by calculating the dot product of the vector sum of the $\mathrm{x}$, $\mathrm{y}$, and $\mathrm{z}$ forces, which act to compress the supporting springs, and the area normal unit vector,

$$
F_{\text {perpend }}=\left(\mathbf{F}_{\mathrm{x}}+\mathbf{F}_{\mathrm{y}}+\mathbf{F}_{\mathrm{z}}\right) \cdot \mathbf{u}_{\mathrm{n}} \text {. }
$$

The perpendicular force was then divided by the area associated with each node in order to determine the interface normal stress,

$$
\sigma_{\text {normal }}=\mathrm{F}_{\text {perpend }} / \mathrm{A} .
$$




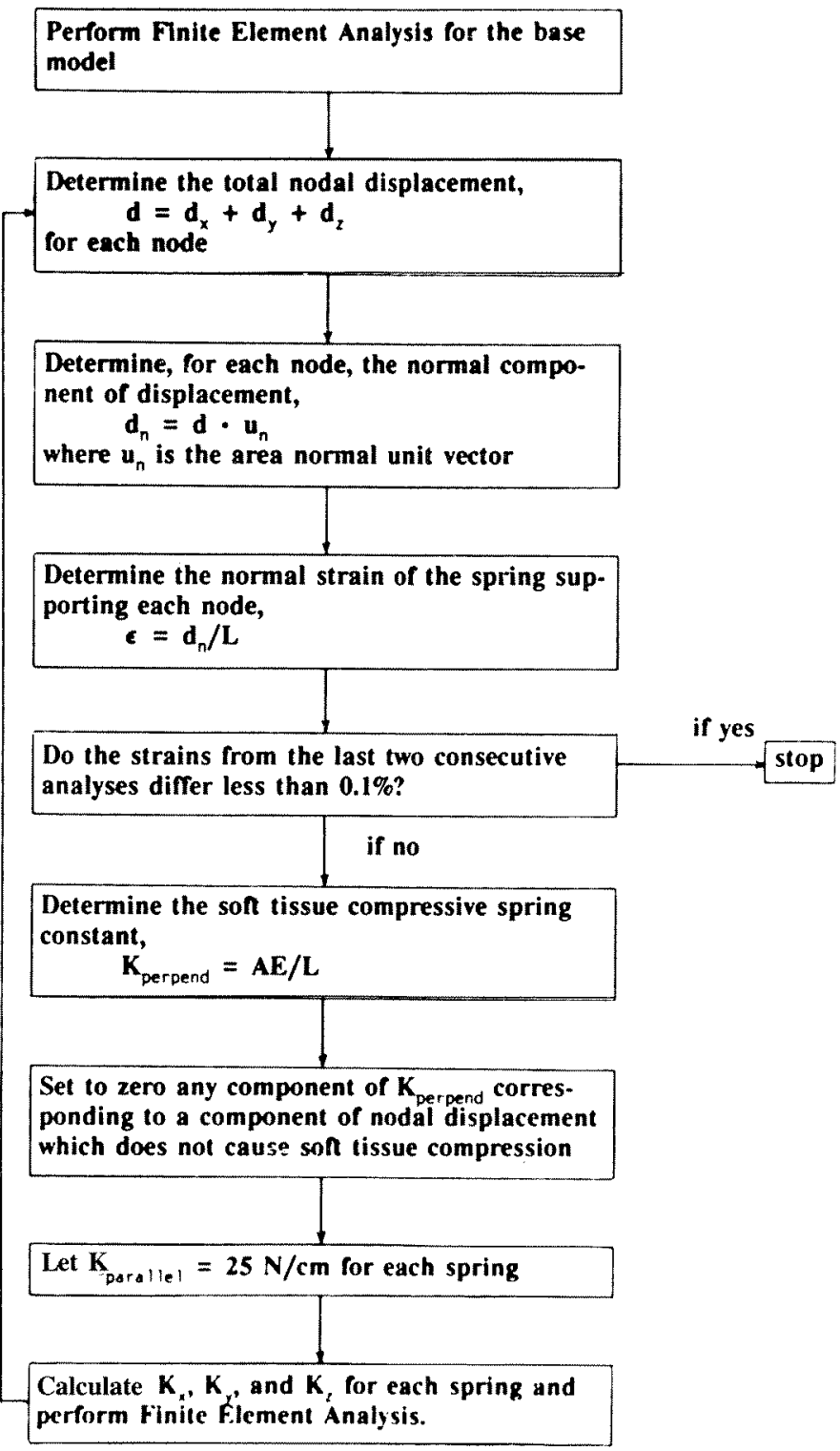

Figure 3.

Flowchart outlining the iterative process of obtaining and analyzing the revised base model, and the altered models.

The calculated normal stress values were compared with the measured normal stresses obtained by other investigators to assess the validity of the results. The shear force at a node was computed as the vector difference between the vector sum of the $\mathrm{x}, \mathrm{y}$, and $\mathrm{z}$ forces which act to compress the supporting spring and the perpendicular force,

$$
F_{\text {shear }}=\left(\mathbf{F}_{\mathrm{x}}+\mathbf{F}_{\mathrm{y}}+\mathbf{F}_{\mathrm{z}}\right)-\mathbf{F}_{\text {perpend }} \text {. }
$$

The shear force at a node was then divided by the area associated with the node to determine the shear stress,

$$
\tau_{\text {shear }}=\mathrm{F}_{\text {shear }} / \mathrm{A} \text {. }
$$

Several altered variations of the base model were developed to determine the effects of various prosthesis changes on the interface normal stresses. For each altered model, the FE analysis was performed in the iterative manner described earlier, and the interface normal and shear stresses were determined. The altered models included:

(1) A model with thicker elements $(t=1.0 \mathrm{~cm})$;

(2) A model with thinner elements $(t=0.25 \mathrm{~cm})$;

(3) A model with an elastic modulus about 2.8 times higher, corresponding to a composite of epoxy and fiberglass (Table 1);

(4) A model with an elastic modulus ten times higher;

(5) A model with an elastic modulus about ten times lower, corresponding approximately to a material such as polystyrene (Table 1);

(6) A model with the socket attached to the prosthesis about $1 \mathrm{~cm}$ from the distal end of the socket, in addition to the proximal attachment;

(7) A model that in the proximal posterior portion of the socket used different values $(a=2,917 ; b=-825.0$; and, $c=298.3$ ) in the equation for $E$ in order to increase $E$ by up to about 40 percent for a given value of $\varepsilon$. (It was thought that this might simulate a more muscularly-toned stump, and that such a stump might sustain greater load in the proximal posterior region and alleviate some of the load in the distal anterior region);

(8) A model with a socket/stump $2 \mathrm{~cm}$ longer;

(9) A model with a socket/stump $2 \mathrm{~cm}$ shorter; and

(10) A model with a suction socket. For this model, constant contact at the entire stump/socket interface is assumed. Since it is possible in this case for the springs representing the soft tissue to be in tension, the springs in this model which are in tension are not given spring constant values of zero as in the other models.

\section{RESULTS}

Socket/stump interface normal and shear stresses were obtained from the analysis of the revised base model. Normal and shear stresses along the anterior, posterior, medial, and lateral aspects of the socket/stump interface are found in Table 3 and Table 4.

Distally, in the revised base model, higher normal stresses were noted along the most anterior aspect of the socket, and proximally, the higher values were posterior and medial (Figure 4). This distribution appears consistent with the applied loading condition. Normal stresses medially and laterally were smaller than those anterior and posterior. Higher medial and lateral stresses were located at the distal and proximal ends. Overall, the highest normal 
Journal of Rehabilitation Research and Development Vol. 28 No. 3 Summer 1991

Table 3.

Maximum and median socket/stump interface normal stresses along the anterior, posterior, lateral, and medial aspects of the revised base model.

\begin{tabular}{ccccc}
\hline $\begin{array}{c}\text { Anterior } \\
\text { Vertical } \\
\text { Location }\end{array}$ & $\begin{array}{c}\text { Normal Stress } \\
\text { Maximum, Median } \\
(\mathbf{K P a})\end{array}$ & $\begin{array}{c}\text { Posterior } \\
\text { Normal Stress } \\
\text { Maximum, Median } \\
(\mathbf{K P a})\end{array}$ & $\begin{array}{c}\text { Lateral } \\
\text { Normal Stress } \\
\text { Maximum, Median } \\
(\mathbf{K P a})\end{array}$ & $\begin{array}{c}\text { Medial } \\
\text { Normal Stress } \\
\text { Maximum, Median } \\
(\mathbf{K P a})\end{array}$ \\
\hline 1.0 & $961 ., 670$. & $25.2,21.3$ & $68.6,63.3$ & $31.6,25.4$ \\
3.0 & $267,221$. & $9.70,8.33$ & $34.6,24.8$ & $20.2,7.76$ \\
5.0 & $62.8,51.5$ & $6.46,4.77$ & $16.0,13.1$ & $6.01,3.34$ \\
7.0 & $1.65,1.24$ & $5.38,4.55$ & $4.68,4.30$ & $1.89,0.0314$ \\
9.0 & $0.893,0.329$ & $8.51,7.52$ & $6.22,4.06$ & $3.55,0.625$ \\
11.0 & $0.952,0.301$ & $21.9,16.6$ & $10.3,3.20$ & $8.86,3.57$ \\
13.0 & $5.08,0.806$ & $34.1,31.3$ & $17.6,2.62$ & $21.6,8.70$ \\
15.0 & $2.47,0.038$ & $49.1,47.0$ & $28.5,5.62$ & $20.4,13.7$ \\
16.0 & $4.15,0.067$ & $74.0,62.6$ & $34.1,6.33$ & $37.7,14.0$ \\
17.0 & $4.65,0.494$ & $128 ., 92.7$ & $28.0,6.49$ & $37.3,6.65$ \\
19.0 & $9.59,0.091$ & $-21.1,1.73$ & $78.3,33.6$ \\
\hline
\end{tabular}

Vertical location is in centimeters from the tip of the stump.

Table 4.

Maximum and median socket/stump interface shear stresses along the anterior, posterior, lateral, and medial aspects of the revised base model.

\begin{tabular}{|c|c|c|c|c|}
\hline $\begin{array}{l}\text { Vertical } \\
\text { Location }\end{array}$ & $\begin{array}{c}\text { Anterior } \\
\text { Shear Stress } \\
\text { Maximum, Median } \\
(\mathbf{K P a})\end{array}$ & $\begin{array}{c}\text { Posterior } \\
\text { Shear Stress } \\
\text { Maximum, Median } \\
(\mathrm{KPa})\end{array}$ & $\begin{array}{c}\text { Lateral } \\
\text { Shear Stress } \\
\text { Maximum, Median } \\
\text { (KPa) }\end{array}$ & $\begin{array}{c}\text { Medial } \\
\text { Shear Stress } \\
\text { Maximum, Median } \\
(\mathbf{K P a})\end{array}$ \\
\hline 1.0 & $463 ., 427$ & $30.4,25.4$ & $49.7,21.8$ & $46.2,42.8$ \\
\hline 3.0 & $110 ., 103$ & $28.8,23.6$ & $29.2,24.1$ & $26.4,24.7$ \\
\hline 5.0 & $25.1,6.56$ & $27.1,22.5$ & $19.3,15.7$ & $21.4,16.2$ \\
\hline 7.0 & $3.41,0.198$ & $26.5,21.7$ & $18.7,13.0$ & $21.4,0.146$ \\
\hline 9.0 & $5.80,2.48$ & $38.0,26.9$ & $18.5,11.8$ & $6.84,48.3$ \\
\hline 11.0 & $3.16,1.20$ & $32.3,28.2$ & $22.0,9.83$ & $25.2,13.1$ \\
\hline 13.0 & $6.83,2.10$ & $51.3,22.1$ & $20.9,7.56$ & $39.4,28.4$ \\
\hline 15.0 & $4.10,3.21$ & $64.7,30.8$ & $35.4,7.59$ & $43.6,21.9$ \\
\hline 16.0 & $6.97,5.71$ & $76.7,36.8$ & $52.7,42.6$ & $67.2,27.1$ \\
\hline 17.0 & $10.8,8.69$ & $86.5,63.2$ & $41.3,34.6$ & $52.9,14.7$ \\
\hline 19.0 & $9.02,4.01$ & --- & $42.7,35.9$ & $55.0,47.0$ \\
\hline
\end{tabular}

Vertical location is in centimeters from the tip of the stump. 


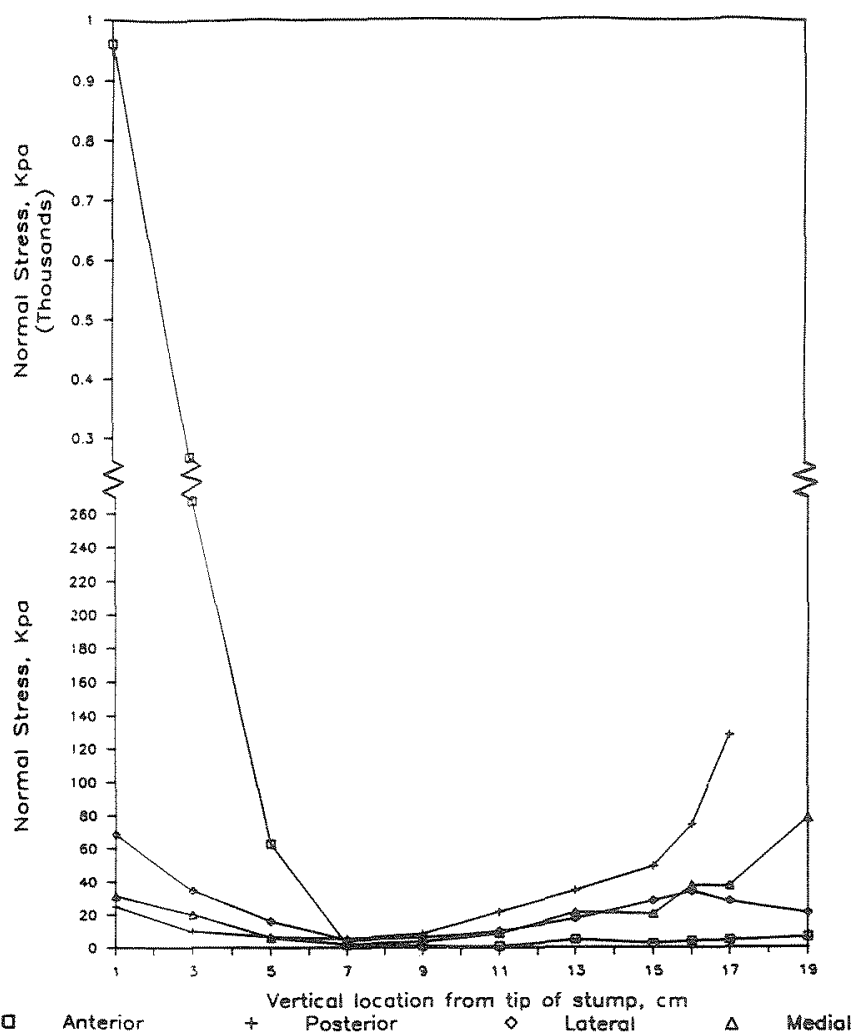

Figure 4.

Stump/socket interface normal stresses (in $\mathrm{KPa}$ ) versus vertical location (in $\mathrm{cm}$ from the distal end of the stump), for the revised base model $(a)$ along the anterior, posterior, lateral, and medial aspects of the interface. stresses were seen in the distal anterior portion of the socket (Figure 4 and Figure 5 ).

Many normal stresses were in excess of values reported (2) to occlude arteriolar blood flow in the thenar eminence (13-16, and 8-11 $\mathrm{KPa}$ under low and high shear conditions, respectively), and those reported (15) to cause transcutaneous oxygen partial pressures to drop to zero (5.6, and 9.5 $\mathrm{KPa}$ over the tibia, and tibialis anterior, respectively). Higher normal stresses can be tolerated, if peak durations are not too long, and have ample time between them.

The maximum anterior, posterior, lateral, and medial normal stresses for the altered models with: element thickness doubled, elastic modulus increased 2.8 times higher, distal as well as proximal end-socket attachment, and stiffer proximal posterior springs, were not notably reduced compared with those of the revised base model (Table 5).

Decreasing element thickness resulted in reductions ranging up to 3 percent in the highest distal anterior normal stresses (Table 5). Interface normal stress increases of up to $9 \mathrm{KPa}$ proximal medially were also found, but values there remained less than 10 percent of the highest distal end normal stress.

A prosthesis elastic modulus 10 times higher produced distal end normal stress decreases of up to about 9 percent (Table 5), with normal stress decreases generally noted throughout. Decreasing the elastic modulus by a factor of 10 produced reductions of up to about 14 percent in the higher distal end normal stresses (Table 5), along with proximal medial normal stress increases of up to about 32 $\mathrm{KPa}$. However, proximal end normal stresses were still much smaller than distal values.

Table 5.

Difference in maximum socket/stump interface normal stresses for altered models with the same length as the revised base model.

\begin{tabular}{ccccc}
\hline $\begin{array}{c}\text { Altered } \\
\text { Model \# }\end{array}$ & $\begin{array}{c}\text { Difference in } \\
\text { Maximum Anterior } \\
\text { Normal Stress } \\
(\mathbf{K P a}, \%)\end{array}$ & $\begin{array}{c}\text { Difference in } \\
\text { Maximum Posterior } \\
\text { Normal Stress } \\
(\mathbf{K P a}, \%)\end{array}$ & $\begin{array}{c}\text { Difference in } \\
\text { Maximum Lateral } \\
\text { Normal Stress } \\
(\mathbf{K P a}, \%)\end{array}$ & $\begin{array}{c}\text { Difference in } \\
\text { Maxium Medial } \\
\text { Normal Stress } \\
(\mathbf{K P a}, \boldsymbol{\%})\end{array}$ \\
\hline 1 & $+5.3,+0.6$ & $+0.8,+0.7$ & $-0.1,-0.2$ & $-2.8,-3.6$ \\
2 & $-31.5,-3.3$ & $-11.5,-9.0$ & $-0.5,-0.8$ & $+9.5,+12.1$ \\
3 & $+0.7,+0.1$ & $-0.2,-0.2$ & $-0.3,-0.5$ & $-2.9,-3.7$ \\
4 & $-37.2,-3.9$ & $-5.6,-4.4$ & $-2.2,-3.2$ & $-6.9,-8.9$ \\
5 & $-134.5,-14.0$ & $-18.9,-14.8$ & $-1.9,-2.8$ & $+31.9,+40.8$ \\
6 & $+14.9,+1.5$ & $+1.6,+1.2$ & $+0.5,+0.8$ & $-3.0,-3.8$ \\
7 & $+0.3,+0.03$ & $+0.02,+0.02$ & $0.0,0.0$ & $-0.1,-0.1$ \\
10 & $-684.3,-71.2$ & $-108.6,-85.1$ & $-40.3,-58.8$ & $-56.4,-72.0$ \\
\hline
\end{tabular}

Altered model \#'s are given on page 5 . 

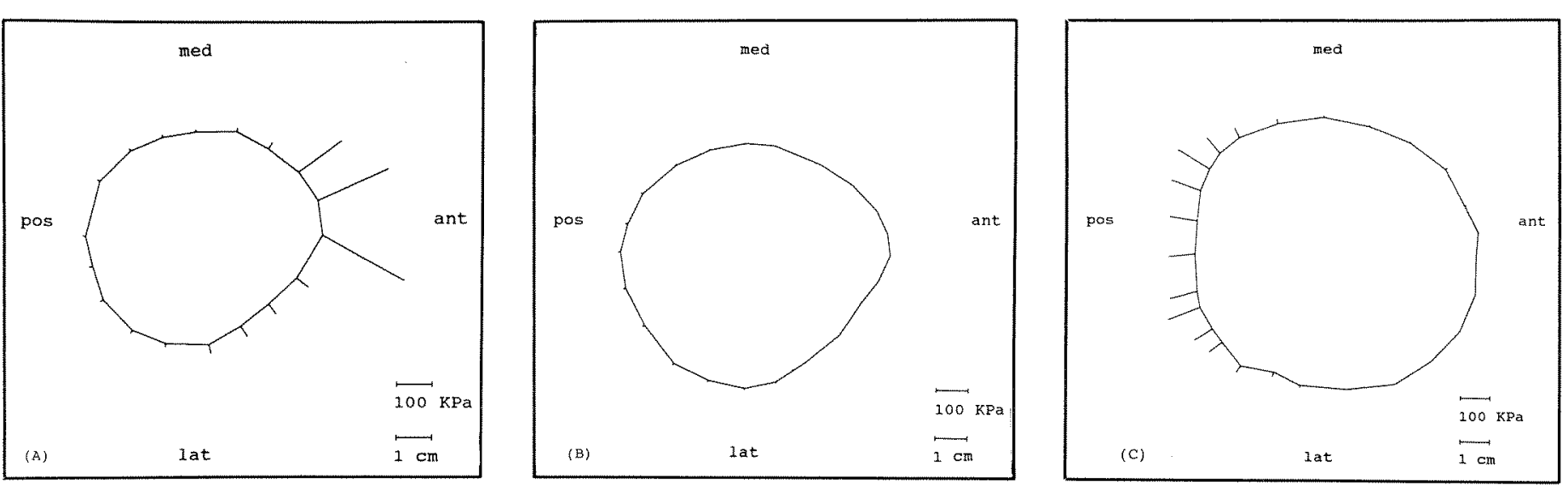

Figure 5.

Porcupine plots of interface normal stress at cross-sections near the $(a)$ distal end; $(b)$ mid-stump; and, $(c)$ proximal end. The length of line indicates magnitude of normal stress.

Increased and decreased stump and socket lengths produced a decrease of approximately 16 percent, and an increase of 18 percent in the maximum distal end normal stresses, respectively, as compared to the revised base model (Figure 6). Level-to-level comparisons should be made cautiously, because the changes in lengths required the addition and deletion of nodes, thereby eliminating node-to-node correspondence between the altered models and the revised base model.

For the altered model simulating a suction socket,

Anterior Aspect of Interface

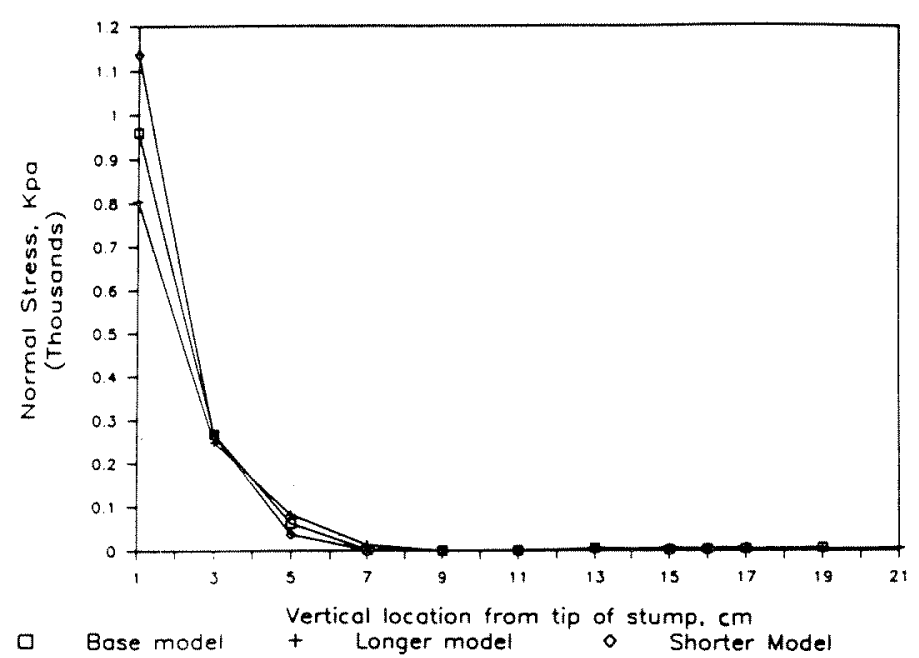

Figure 6a.

Stump/socket interface normal stresses (in $\mathrm{KPa}$ ) for the longer and shorter altered models and the revised base model along the anterior aspect. normal stresses were found to be reduced by as much as 71 percent (from 961 to $276 \mathrm{KPa}$ ) distal anteriorly (Table 5).

Shear stresses in the distal portion of the revised base model were highest along the anterior aspect of the stump. Shear stresses calculated in the proximal portion of the stump were found to be highest along the posterior aspect. Shear stresses along the medial and lateral aspects of the socket tended to gradually increase toward the distal and proximal ends. Changes in shear stresses for altered models tended to mirror changes in interface normal stresses. In

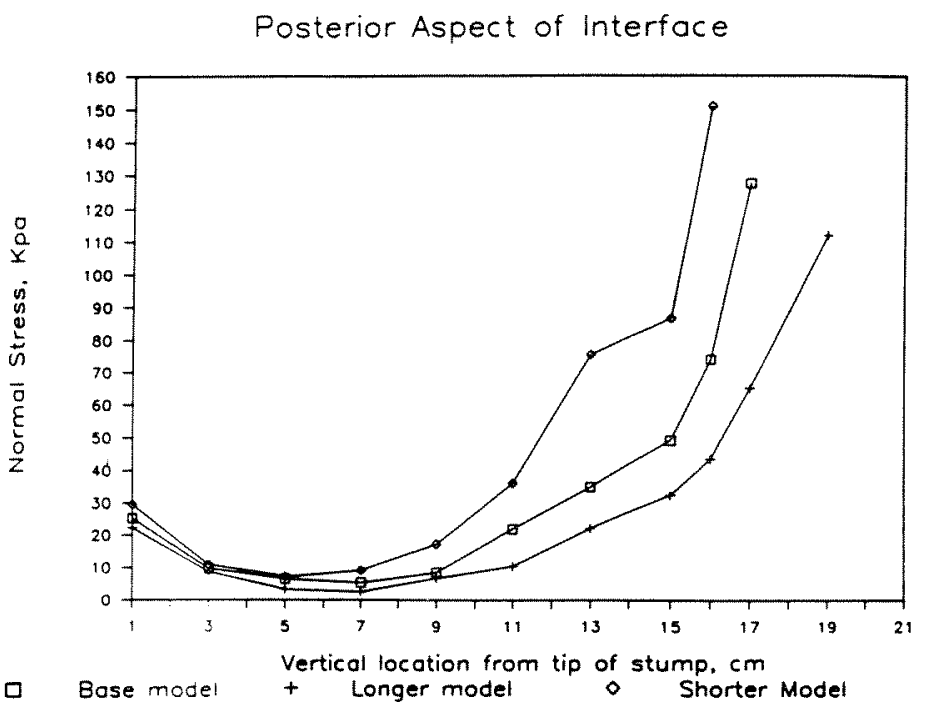

Figure 6 b.

Stump/socket interface normal stresses (in $\mathrm{KPa}$ ) for the longer and shorter altered models and the revised base model along the posterior aspect. 


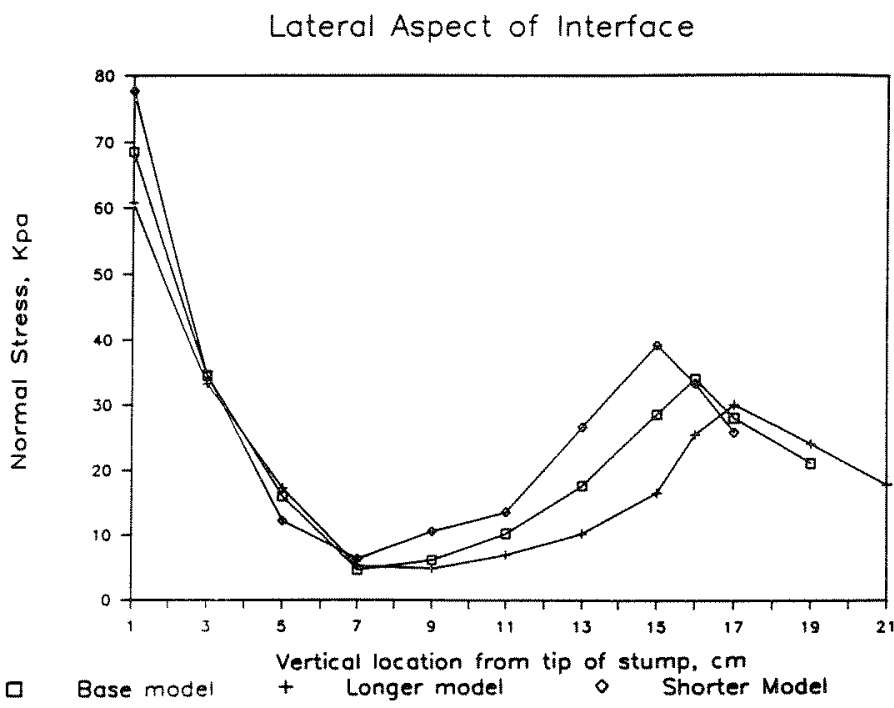

Figure 6c.

Stump/socket interface normal stresses (in $\mathrm{KPa}$ ) for the longer and shorter altered models and the revised base model along the lateral aspect.

each case, only shear stress magnitudes have been compared, not directions.

\section{DISCUSSION}

The results of this study compared favorably with measurements of other investigators. For a BK amputee standing with weight equally distributed on the sound and prosthetic limbs, Steege et al. (18) measured normal stresses from 0 to $128 \mathrm{KPa}$, and calculated normal stresses from 0 to $300 \mathrm{KPa}$. Although these values were considerably lower than those obtained in this study, some of the disparity may be due to the more severe loading condition used in this study (i.e., heelstrike). Corell (4) measured average peak normal stresses at the anterior tip of BK stumps of about $450 \mathrm{KPa}$; however, peaks were as high as $800 \mathrm{KPa}$ for hard sockets. Average peak normal stresses measured at the medial tibial condyle (approximately 140 $\mathrm{KPa}$ ) were slightly higher than those measured at the lateral tibial condyle (approximately $125 \mathrm{KPa}$ ). The results of this study are consistent with Corell's work in that medial normal stresses are greater than lateral normal stresses, although this study found much lower stresses for both locations (up to $78 \mathrm{KPa}$ medially). Distal anterior normal stresses for the present study fall above the range of peak values reported by Corell. This difference may be accounted

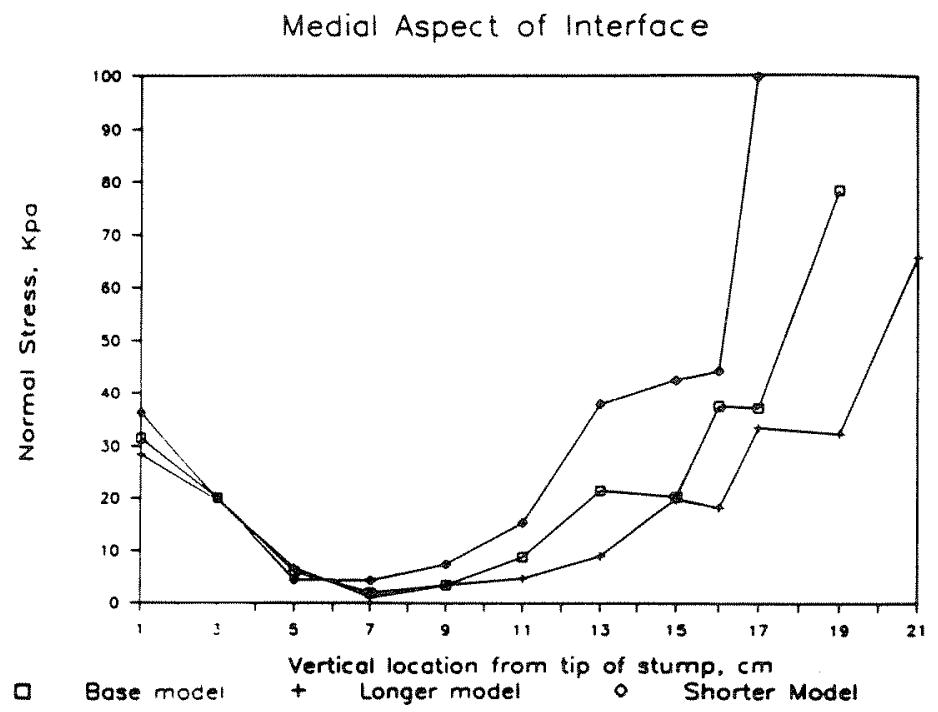

Figure 6d.

Stump/socket interface normal stresses (in $\mathrm{KPa}$ ) for the longer and shorter altered models and the revised base model along the medial aspect versus vertical location along socket/stump (in $\mathrm{cm}$ from the distal end of the stump).

for by the assumption of uniform initial load distribution. Prosthetists attempt to transmit load proximally to the tibial flares, away from the distal anterior stump. Further, inherent in socket modulus is the assumption of a hard socket without stump socks or soft liner.

For BK amputees wearing prostheses of the PTB design, Pearson et al. (11) measured maximum distal anterior normal stresses at heelstrike of about $300 \mathrm{KPa}$. Maximum normal stresses measured at the lateral and medial condyles were about $140 \mathrm{KPa}$ and $50 \mathrm{KPa}$, respectively. These measurements are consistent in magnitude with our results. Medial and lateral distribution of stress is obviously quite dependent on prosthesis alignment. Rae and Cockrell determined distal anterior normal stresses for $\mathrm{BK}$ hard sockets to be variable, but maxima averaged about $520 \mathrm{KPa}(12)$.

For AK amputees, Naeff and Van Pijkeren (8) measured normal stresses in the proximal socket that ranged from 0 to $230 \mathrm{KPa}$. These values were lower than ours. However, AK stumps typically have fewer bony prominences and more soft tissue than BK stumps, which could result in fewer areas of concentrated normal stress, and more surface area over which to distribute force.

Interface shear stresses would seem clinically important, since "pistoning" is a frequent complaint of amputees. Further, the work of Bennett et al. (2) suggests that shear stress is roughly one-half as effective as normal stress at 
Journal of Rehabilitation Research and Development Vol. 28 No. 3 Summer 1991

occluding arterioles. The effects of normal and shear stress were noted to be additive, in that normal stress, in combination with shear, produced occlusion at lower normal stresses than normal stress alone. The validity of calculated interface shear stresses is open to question due in large part to the no-slip condition of the model. Naeff and Van Pijkeren, in their study of AK amputees, argue that skin is mobile, resulting in a small shear force. Sanders et al. (16) report a maximum shear stress at the socket/ stump interface during gait of approximately $50 \mathrm{Kpa}$. Since our normal stresses are somewhat higher than experimental reports, it would seem consistent that our shear calculations are also greater than reported measured values.

The large difference between the normal stresses at the most anterior nodes and the normal stresses at adjacent nodes was a notable trend. These differences were mainly a function of the soft tissue thickness values assigned to those nodes. Since the springs supporting the nodes located on the subcutaneous border of the tibia were given thickness values $(0.35 \mathrm{~cm})$ less than half those of the springs supporting the adjacent nodes $(0.75 \mathrm{~cm})$, the calculated strains were much higher (Table 2) at these nodes (strain is inversely proportional to thickness). These higher strains resulted in higher elastic moduli, which resulted in higher spring constant values, leading to higher calculated normal stress values. While measured at normal stresses too low for application to this analysis, Sangeorzan et al. (15), reported stiffness of soft tissue over the tibia to be 2.5 to 7 times greater than the stiffness of soft tissue over the tibialis anterior. The tissue stiffness on the subcutaneous border of the tibia resulting from our selection of tissue thickness is 6 times greater than over the tibialis anterior (Table 2). Accuracy of our analysis might be improved by the use of more accurate values of soft tissue thickness or more accurate soft tissue moduli.

The maximum distal normal stresses obtained in this study for the revised base model are within a standard deviation of the normal stress tolerance values at mid-tibia reported by Fischer (5) $(1020 \pm 220 \mathrm{Kpa}$ for men, and 870 $\pm 340 \mathrm{Kpa}$ for women), indicating that the tolerance of some individuals might be exceeded at the distal end. Thus, distal normal stress reduction, perhaps with increased normal stress elsewhere, would be a reasonable objective.

The results of this study indicate that doubling prosthesis thickness, increasing prosthesis elastic modulus by about three times, adding distal end-socket attachment, or increasing proximal posterior soft tissue stiffness will do little to reduce interface normal stresses in this static model. In fact, decreasing the thickness by half, and decreasing the modulus by 10 times, could reduce maximum distal end interface normal stresses. The results of the thinner and lower modulus models are reasonable, since a more flexible prosthesis could result in greater deformation of the prosthesis, rather than deformation of soft tissue. However, an increase in model modulus by a factor of 10 results in decreased distal anterior normal stresses, suggesting a maximum in these normal stresses with intermediate modulus prostheses. This appears to be due to changes in anterior stump/socket contact area. The low modulus socket is able to deform, with high displacement of the prosthesis relative to the socket, providing greater distal anterior contact between socket and stump. As the modulus increases, the prosthesis and socket begin to approximate a rigid body with respect to the soft tissue, resulting in decreased distal anterior contact area. With the prosthesis and socket already approximating a rigid body relative to the soft tissue, further increases in modulus result in further decreases in relative displacement between socket and prosthesis which begins to cause increased distal anterior contact. The results of the model with a modulus ten times higher are due to reduced displacement of the socket, resulting in an increase in the length of socket which displaces posteriorly (i.e., distal position), causing anteriorly-directed forces. Subsequently, the distal anterior forces are reduced in order to maintain moment equilibrium.

Decreasing the elastic modulus of the prosthesis appears to have the greatest potential for improving the interface normal stresses with conventional sockets. Plastic deformation and fatigue failure of the prosthesis limit the extent to which prosthesis elastic modulus can be decreased.

The results of stump length variation revealing lower normal stresses with a longer residual limb concur with clinical experience. The inability of the prosthetist to control limb length minimizes the usefulness of these results. However, these findings suggest that even a little extra length retained at surgery $(2 \mathrm{~cm})$, either initially or at revision, may effect benefits from normal stress reduction.

The greatest reductions in stump normal stress were calculated with the use of a suction socket because it permits tensile stresses normal to the interface to be transmitted between the stump and socket. Prosthetists do not commonly fit BK amputees with suction sockets, citing the lack of soft tissue, limb shape, and frequent limb volume fluctuations as complications (13).

The results of this study have been obtained with a load condition applied to simulate heelstrike. Thus, suggested changes could adversely affect the interface normal stresses during other portions of the gait cycle. It should further be noted that since the models are assumed to be composed of an elastic material with a linear modulus, 
and since the supporting springs are also assumed to be ideal (i.e., no energy dissipated), the results obtained in this study cannot account for any damping or other nonideal characteristics which might have significance.

Subsequent analytical studies should investigate other portions of the gait cycle, as well as attempt to consider nonlinear effects. Experimental studies should seek to verify results obtained in this study so that faster, less expensive analytical studies can be used to optimize prosthetic components.

\section{CONCLUSIONS}

While the results obtained in this study are specific to the prosthesis modeled, the following comments are appropriate:

1. Socket/stump interface normal stresses can be reduced by use of lower modulus prosthetic materials and thinner fabrication, thereby providing greater deformation of the prosthesis with less deformation of soft tissue.

2. Relatively small changes in length can considerably alter the interface normal stresses, with increased length resulting in lower normal stresses.

3. Suction socket suspension allows for transmission of tensile stress to the soft tissue, resulting in lower interface normal stresses.

\section{ACKNOWLEDGMENTS}

This study was supported by the American Federation for Aging Research and the National Science Foundation. The Veterans Administration Rehabilitation Research and Development Service also contributed to the completion of this work. The authors are indebted to Mary Hurtado for her assistance in typing the manuscript, and Judith Simon for assistance in editing.

\section{REFERENCES}

1. Barbenel JC, Evans JH, Finlay JB: Stress-strain-time relations for soft connective tissues. In Perspectives in Bioengineering, 165-172, R.M. Kenedi (Ed.). Baltimore: University Park Press, 1973.

2. Bennett L, Kauner D, Lee BK, Trainor FA: Shear vs. pressure as causative factors in skin blood flow occlusion. Arch Phys Med Rehabil 60:309-314, 1979.

3. Breakey J: Gait of unilateral below-knee amputees. Orthot Prosthet 30:17-24, 1976.

4. Corell EB: Normal pressure distributions applied by total contact below-knee prostheses. In Technical Report No. 9 , Orthotics Research Project. Department of Physical Medicine and Rehabilitation. Ann Arbor: University of Michigan, 1969.

5. Fischer AA: Pressure tolerance over muscles and bones in normal subjects. Arch Phys Med Rehabil 67:406-409, 1986.

6. Hoaglund FT, Jergesen HE, Wilson LA, Lamoreux LW, Roberts RA: Evaluation of problems and needs of veteran lower-limb amputees in the San Francisco Bay area during the period 1977-1980. J Rehabil Res Dev 20(1):57-71, 1983.

7. Huiskies R, Chao EYS: A survey of finite element analysis in orthopedic biomechanics: The first decade. $J$ Biomech 16:385-409, 1983.

8. Naeff M, Van Pijkeren T: Dynamic pressure measurements at the interface between residual limb and socket: The relationship between pressure distribution, comfort, and brim shape. Bull Prosthet Res 17(1):35-50, 1980.

9. Nakamura S, Crowninshield RD, Cooper RR: An analysis of soft tissue loading in the foot: A preliminary report. Bull Prosthet Res 18(1):27-34, 1981.

10. Nissan M: A simplified model for the short-below-knee stump. J Biomech 10:651-658, 1977.

11. Pearson JR, Holmgren G, March G, Oberg K: Pressures in critical regions of the below-knee patellar-tendon-bearing prosthesis. Bull Prosthet Res 10-19:52-75, 1973.

12. Rae JW, Cockrell JL: Interface pressure and stress distribution in prosthetic fitting. Bull Prosthet Res 10-16:64-111, 1971.

13. Roberts RA: Suction socket suspension for below-knee amputees. Arch Phys Med Rehabil 67:196-199, 1986.

14. Robinson JL, Smidt GL, Arora JS: Accelographic, temporal and distance gait factors in below-knee amputees. Phys Ther 57:898-904, 1977.

15. Sangeorzan BJ, Harrington RM, Wyss CR, Czerniecki JM, Matsen FA: Circulatory and mechanical response of skin to loading. J Orthop Res 7:425-431, 1989.

16. Sanders JE, Boone DA, DAly CM: The residual limb/prosthetic socket interface: Normal stress and shear stress. In Proceedings of the 13th Annual RESNA Conference, Washington, DC, 234-235, 1990.

17. Skinner HB, Effeney DJ: Gait analysis in amputees. $A m J$ Phys Med 64:82-89, 1985.

18. Steege JW, Schnur DS, Childress DC: Prediction of pressure at the below-knee socket interface by finite element analysis. In Symposium on the Biomechanics of Normal and Prosthetic Gait, Boston, MA, 1987.

19. Suzuki K: Force plate study on the artificial limb gait. J Jap Orthop Assn 46:503-516, 1972. 
Journal of Rehabilitation Research and Development Vol. 28 No. 3 Summer 1991

20. Waters RL, Perry J, Antonelli D, Hislop H: Energy cost of walking of amputees: The influence of level of amputation. J Bone Joint Surg 58-A:42-46, 1976.

21. Effeney DJ, Krupski W, Skinner HB: Amputations. In Current Surgical Diagnosis and Treatment, 7th Edition,
702-711, L. Way (Ed.). Los Altos, CA: Lange Medical Publications, 1985.

22. Lynch CT (Ed.): Non-metallic materials and applications. In: CRC Handbook of Materials Science: Vol. III, 21, 47, 60. Cleveland: CRC Press, 1975. 